\title{
Resveratrol comes of age
}

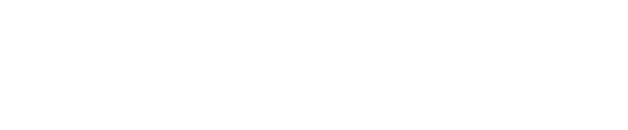

\section{Roger M Pinder}

International Journal of Wine Research, York, UK
Correspondence: Roger M Pinder 2 St Wilfrid's Court, Monkgate, York YO3I 7UQ, UK

$\mathrm{Tel}+441904646684$

Email roger.pinder@gmail.com
There is substantial evidence that moderate consumption of alcohol is associated with a lower risk of mortality, ${ }^{1,2}$ cardiovascular disease, ${ }^{3}$ stroke, ${ }^{4}$ type 2 diabetes, $, 5,6$ and cognitive decline and dementia in old age. ${ }^{7-9}$ It is still not proven whether wine consumption is associated with lower risks than consumption of other forms of alcohol such as beer or distilled spirits, but systematic reviews suggest that this may be the case at least for cognitive decline and dementia. ${ }^{710}$ However, a causal relationship has been questioned by some, with suggestions that health status and social factors may confer the benefits, ${ }^{11,12}$ especially for wine drinkers who are more often female, better educated, health conscious, non-smokers and temperate drinkers. ${ }^{13}$ Nevertheless, plausible biological mechanisms explain the benefits of alcohol and wine, and the relative specificity of the inverse relationship of moderate drinking to various human ailments is a strong point for causality. ${ }^{10}$

Wine has unique properties quite separately from its alcohol content. ${ }^{10}$ Unlike beer and spirits, wine contains a variety of polyphenolic compounds which are extracted from the grapes during vinification. Mainly in the form of flavonoids like quercetin and stilbenes such as resveratrol, these polyphenols are contained in grape tannins and anthocyanin pigments and achieve higher levels in red than in white or rosé wines. Nevertheless, they are present in only small quantities, corresponding to about $250 \mathrm{mg} / \mathrm{L}$ in white and $1500 \mathrm{mg} / \mathrm{L}$ in red wines.

Resveratrol is just a minor component but has received the greatest research and lay attention, and ways have been described to enhance vastly its content in wine. ${ }^{14}$ Resveratrol, like all wine polyphenols, has antioxidant properties but also seems to modulate nitric oxide synthesis and promote vasodilatation. Importantly, it attenuates amyloid neuropathology in cell and animal models of Alzheimer's disease, and restores cognitive function. ${ }^{10}$ Its ability to enhance the effects of a family of longevity genes called sirtuins ${ }^{15}$ has led to the synthesis of analogs of resveratrol, one of which, SRT501, has recently completed clinical trials in diabetes and obesity.

Resveratrol is a mixture of cis- and trans-isomers. Most of the research has been carried out with the naturally occurring trans-isomer, which is found in peanuts and Japanese knotweed as well as wine grapes and various types of berries. Until recently, the oral bioavailability problem of both flavonoids and stilbenes has been a stumbling block to proper research in humans - they are well absorbed when taken orally but are rapidly metabolized and eliminated. Glucoside derivatives of quercetin did demonstrate better bioavailability than quercetin itself when given orally, and resulted in inhibition 
of platelet aggregation. ${ }^{18}$ However, plasma concentrations of resveratrol and its metabolites are low and transient after oral administration of the compound itself or in the form of red wine. ${ }^{16,17}$ Furthermore, faced with the very low bioavailability of resveratrol and the poor chances of a polar and scarcely lipophilic molecule passing the blood-brain barrier to achieve pharmacologically active levels in the human brain, any prospects of measuring a central effect were long regarded as minimal. Nevertheless, the application of modern brain imaging technology has recently defied the odds and demonstrated a central action of oral resveratrol. ${ }^{19}$

David Kennedy and colleagues at Northumbria University in the UK assessed localized cerebral blood flow variables and cognitive performance in 22 healthy human adults in a randomized, double-blind, placebo-controlled, crossover study using near-infrared spectroscopy. ${ }^{19}$ The presence of resveratrol and its conjugates/metabolites in plasma were confirmed after the same doses of 250 or 500 mg of trans-resveratrol in a separate cohort. Resveratrol administration produced dose-dependent increases in cerebral blood flow during performance of a selection of cognitive tasks that activate the frontal cortex. Enhanced oxygen extraction was also apparent during task performance after both doses of resveratrol, although cognitive function was unaffected.

It seems that, in addition to the association of moderate wine consumption with a lowered risk for cognitive decline and dementia, ${ }^{10}$ one of the many polyphenols contained in wine may actually enter the brain after oral administration and activate cerebral blood flow upon cognitive demand. ${ }^{19}$ Given the very real effects of resveratrol on Alzheimer's disease neuropathology and the associated cognitive deficits in animal models, it may well be worth considering a clinical trial of resveratrol in cognitively impaired older humans or in predementia syndromes like mild cognitive impairment. The latest data should encourage the search for synthetic analogs of wine polyphenols, particularly resveratrol, which will have greater oral bioavailability and enhanced brain penetration for the treatment of cognitive decline and dementia.

\section{References}

1. Costanzo S, Di Castelnuovo A, Donati MB, et al. Alcohol consumption and mortality in patients with cardiovascular disease. J Am Coll Cardiol. 2010:55;1339-1347.

2. Mukamal KJ, Chen CM, Sowmya RR, et al. Alcohol consumption and cardiovascular mortality among US adults, 1987-2002. J Am Coll Cardiol. 2010;55:1328-1335.

3. Hvidtfeldt UA, Tolstrup JS, Jakobsen MU, et al. Alcohol intake and risk of coronary heart disease in younger, middle-aged, and older adults. Circulation. 2010;121:1589-1597.

4. Reynolds K, Lewis LB, Nolen JDJ, et al. Alcohol and the risk of stroke. A meta-analysis. JAMA. 2003;289:579-588.

5. Koppes LLJ, Bouter LM, Dekker JM, et al. Moderate alcohol consumption lowers the risk of type 2 diabetes. Diabetes Care. 2005;28:719-725.

6. Joosten MM, Grobbee DE, van der A DL, et al. Combined effect of alcohol consumption and lifestyle behaviors on risk of type 2 diabetes. Am J Clin Nutr. 2010;doi:10.3945/ajen.2010.29170.

7. Peters R, Peters J, Warner J, et al. Alcohol, dementia and cognitive decline in the elderly: a systematic review. Age Ageing. 2008;37:505-512.

8. Panza F, Capurso C, D'Introno A, et al. Alcohol drinking, cognitive functions in older age, predementia, and dementia syndromes. J Alzheimers Dis. 2009;17:7-31.

9. Anstey KJ, Mack HA, Cherbuin N. Alcohol consumption as a risk factor for dementia and cognitive decline: Meta-analysis of prospective studies. Am J Geriatr Psychiatry. 2009;17:542-555.

10. Pinder RM. Does wine prevent dementia? Int J Wine Res. 2009; $1: 41-52$.

11. Hansel B, Thomas F, Pannier B, et al. Relationship between alcohol intake, health and social status, and cardiovascular risk factors in the urban Paris-Ile-de-France cohort: is the protective action of alcohol a myth? Eur J Clin Nutr. 2010; doi:10.1038/ejcn.2010.61.

12. Anstey KJ, Cherbuin N. Is it the wine, alcohol in general, or the social context of alcohol drinking that confers health benefits? Int J Wine Res. 2010;2:9-11.

13. Klatsky AL, Friedman GD, Armstrong MA, et al. Wine, liquor, beer and mortality. Am J Epidemiol. 2003;158:585-595.

14. Norrie PA Resveratrol-enhanced wine. Int J Wine Res. 2009;1: 187-188.

15. Bauer JA, Pearson KJ, Price NL, et al. Resveratrol improves health and survival of mice on a high-calorie diet. Nature. 2006;444:337-342.

16. Walle T, Hsieh F, Delegge MH, et al. High absorption but very low bioavailability of oral resveratrol in humans. Drug Metab Dispos. 2004;32:1377-1382.

17. Vitaglione P, Sforza S, Galaverna G, et al. Bioavailability of trans-resveratrol from red wine in humans. Mol Nutr Food Res. 2005;49:495-504.

18. Hubbard GP, Wolffram S, Lovegrove JA, et al. Ingestion of quercetin inhibits platelet aggregation and essential components of the collagenstimulated platelet activation pathway in humans. J Thromb Haemost. 2004;12:2138-2145.

19. Kennedy DO, Wightman EL, Reay JL, et al. Effects of resveratrol on cerebral blood flow variables and cognitive performance in humans: a double-blind, placebo-controlled, crossover investigation. Am J Clin Nutr. 2010;doi:10.3945/ajen.2009.28641.

International Journal of Wine Research

\section{Publish your work in this journal}

The International Journal of Wine Research is an international, peer-reviewed open-access, online journal focusing on all scientific aspects of wine, including: vine growing; wine elaboration; human interaction with wine; and health aspects of wine. The journal provides an open access platform for the reporting

of evidence based studies on these topics. The manuscript management system is completely online and includes a very quick and fair peer-review system, which is all easy to use. Visit http://www.dovepress.com/testimonials.php to read real quotes from some of our published authors. 